\title{
The introduction of real numbers in secondary education. An institutional analysis of textbooks
}

\author{
Alejandro S. González-Martín*; Victor Giraldo**; Alexandre M. Souto*** \\ * Département de Didactique, Université de Montréal (Canada) \\ ** Instituto de Matemática, Universidade Federal do Rio de Janeiro (Brazil) \\ *** Colégio Pedro II (Brazil)
}

\begin{abstract}
In this paper we analyse the introduction of irrational and real numbers in secondary textbooks, as they are proposed to be taught, from a sample of Brazilian textbooks used in public schools and approved by the Ministry of Education. The analyses discussed in this paper follow an institutional perspective (using Chevallard's Anthropological Theory of Didactics). Our results indicate that the notion of irrational number is generally introduced on the basis of the decimal representation of numbers, and that the mathematical need for the construction of the field of real numbers remains unclear in the textbooks. It seems that textbooks used in secondary teaching institutions develop mathematical organisations which focus on the practical block.
\end{abstract}

Keywords: real numbers; irrational numbers; textbooks analysis; praxeology; mathematical organisation

\section{Introduction and rationale}

Traditionally, in elementary school, the introduction of the set of integers is based on the algebraic limitations of the set of natural numbers. This construction is motivated by some "daily life" problems in which it is necessary to find the difference between two natural numbers, the first being smaller than the second. Similarly, the extension from integers to rational numbers involves the limitation of the operation of division, illustrated by some practical problems. Even the construction of complex numbers at 
higher educational levels is grounded in the algebraic structure of the field of real numbers (which is assumed to be previously known), namely the impossibility of finding roots for some polynomial equations. Therefore, the learning of different sets of numbers can be seen as a progressive extension of the initial perception of numbers through the algebraic structure of nested number sets, from the primitive notion of counting, to the ideas of comparing, measuring and solving equations.

The case for the extension from rational to real numbers is particularly dramatic. Unlike the previous extensions, this is not an algebraic jump, as it formally requires theoretical properties such as convergence and completeness. This has proved to be a crucial obstacle, which began with the incommensurable magnitudes debate in Greek mathematics (e.g. Katz 1992, pp. 73-74). Moreover, only a discrete set of numbers is enough to deal with the empirical problem of measurement, whilst the system of real numbers accounts for the construction of a theory of measure consistent with classical geometry. Therefore, the need to construct the set of real numbers can hardly be established or concretized upon empirical motivations. As research has shown (see section 3), these epistemological obstacles and theoretical constraints have repercussions both in teaching and in learning. On the one hand, a formal definition of real number is surely incompatible with elementary and secondary school. On the other hand, the set of real numbers cannot be built upon empirical or algebraic demands ${ }^{\mathrm{i}}$. Nevertheless, real numbers are an indispensable topic in school mathematics education due to: (1) their inherent importance in the core of contemporary mathematical knowledge; and (2) their entangled relation with many other equally important elementary topics (such as the circle length, square roots, and the Pythagorean Theorem) and advanced topics such as limits and continuity. This poses a key question both for teaching, and for textbooks and syllabi design: How can balance be achieved 
between rigour and intuition in the particularly delicate case of the construction of real numbers in elementary school?

In our opinion, the main difficulties in motivating the introduction of real numbers have customarily been disregarded or simply bypassed by the approach the institutions usually follow. However, the real line structure, which is at the heart of the theoretical grounding of effectively all infinitesimal calculus definitions, is tacitly assumed to be well understood by students when more advanced mathematical practices, such as derivation or limits, are introduced at later stages of the curriculum. Parallels may be drawn with other topics, such as continuity, sequences and series, which are also assumed to be well known and used as a basis to introduce higher mathematical topics. The research summarised in this paper is part of a broader research project that focuses on the approaches privileged by the institutions (mainly through syllabi, school textbooks, and teacher practices) to introduce curricular topics with the following characteristics: (1) they play a key theoretical role in contemporary mathematics; (2) they form a basis for other (both elementary and more advanced) mathematical objects; (3) they have traditionally been given lesser attention in elementary and secondary school education, but are assumed to be well understood when more advanced topics are taught. Partial results for the case of continuity have been presented in Giraldo, González-Martín and Santos (2009), and for series of real numbers in González-Martín, Nardi and Biza (2011).

It is not our aim to address the issue of how real numbers should be taught in secondary education at this stage of our research; however we expect that our research will contribute to this discussion and that it may lead to finding some answers. 


\section{Research setting}

Research literature has pointed out some difficulties in learning real and irrational numbers, as we will discuss in the following section. Surprisingly, we have not found a significant number of papers focusing on the teaching of these topics. Therefore, being aware of the difficulties identified by research on learning real numbers, we aim to analyse how these numbers are introduced and what significance is given to them in secondary school textbooks.

In other words, the main focus of this paper is to discuss the results of our analyses about the institutional relationship with real numbers in secondary education textbooks, and the way in which they introduce real and irrational numbers. The characterisation of this institutional relationship is based on the analysis of a wide sample of textbooks used in public schools. At this stage of our research, and given the size of the sample, we chose to limit ourselves to the analysis of textbooks, which are an essential part of teaching "used by virtually every teacher and student [...] on a daily basis” (Reys \& Reys 2007, p. 63). The study of how secondary teachers use these textbooks will be the source of future works. We begin by discussing our data concerning the presentation of the content, followed by a focus on the structure of the theoretical explanations, as well as a look at the tasks proposed.

Another important contribution of this paper is to discuss the potential of the use of institutional approaches to identify key questions about the organisation of the teaching of real numbers and the tasks which are privileged. Our analyses allowed us to create a picture of the practical and theoretical discourses fostered by the textbooks, and to draw conjectures about their possible influence on students’ learning. 


\section{Literature review}

The difficulties experienced by students and even by teachers with real numbers or some of their properties have been addressed by research. However, there seems to be very few research papers focusing on the introduction of this topic in school textbooks. The current literature review follows three axes: first, a summary of literature about difficulties experienced by teachers and students with real numbers; secondly, a summary of literature about textbook analysis; and finally, a summary of the main results of Bronner’s (1997) work about real numbers in school textbooks.

Some difficulties identified by the literature concerning irrational numbers are related to their definition, or with the ability to explain the necessity of extending the field of rationals (e.g. Soares, Ferreira and Moreira 1999). Some authors (e.g. Robinet 1986; Fischbein, Jehiam and Cohen 1995) have also identified the idea that an irrational number is a number with an infinite decimal representation (with no consideration for the presence or the absence of a period), or the fact that many prospective teachers associate irrational numbers exclusively to square roots and to $\pi$ (e.g. Sirotic and Zazkis 2007). Research has also identified the fact that many teachers do not recognise nonperiodic, infinite decimal representations as a representation for irrational numbers (Sirotic and Zazkis 2007) and that they do not know for certain that a number represented as a quotient of integers is always a rational number, since they are unable to justify this fact (Zazkis and Sirotic 2004). Further difficulties have been identified concerning the cardinality of number sets and the topological properties of real numbers. For instance, through the idea that for every rational, there is an irrational (Sirotic and Zazkis 2007; Zazkis and Sirotic 2004), or even seeing irrational numbers as a few isolated numbers, or holding atomistic models for the real line, with the numbers one after the other with gaps (Robinet 1986). Finally, at the undergraduate level, Bergé 
(2008) argues that, in general, the completeness property is implicit in the tasks presented in the initial courses. As a consequence, students take it for granted, and develop an intuitive idea without problematizing the need for the property.

In relation to research concerning textbook analysis, research literature in mathematics education contains a lacuna of textbook analyses (e.g. Howson, 1995), in spite of the fact that textbooks "have always played a major role in mathematics education.” (Sträßer 2009, p. 70) Moreover, studies on textbook analysis usually consider a small sample. One recent example is Raman’s (2004) study, who focused on continuity in pre-calculus, calculus, and real analysis courses, but considered only one textbook for each of the three courses analysed. Furthermore, Lithner (2004) analysed the types of reasoning that calculus textbook exercises might instil and develop in the students, but again, restricted his analysis to one textbook to study different types of reasoning and to three textbooks to analyse the use of these different ways of reasoning in problem solving. Litner showed that tasks for which students need merely to reproduce exemplified techniques are predominant in the assignments, but this author did not consider how the content is organised in the textbooks and the possible knowledge that students are lead to develop. More recently, Stylianides' (2009) study analysed a middle school mathematics textbook series to see how reasoning-andproving tasks are promoted in the algebra, number theory, and geometry units.However, this author did not consider the theoretical sections of the textbook series he analysed. Finally, we can cite Wagner’s (2012) study about the grammatical structure of the middle school series, Understanding Mathematics, for which he is the co-author. Although these four authors' investigations, Lithner, Roman, Stylianides, and Wagner, represent important contributions, they only analyse a reduced sample of textbooks and 
they fail to address the possible consequences of the structure of the contents and the types of tasks used to stimulate the students’ learning of mathematical topics.

One particular work which analyses textbooks in order to identify how they introduce real numbers, is Bronner’s (1997) study, which follows and institutional approach and states that textbooks play a significant role in the construction of an institutional relationship with mathematical topics within an institution (p. 58). This researcher uncovers a lack of explicit characterisation of some square roots as being "new numbers" in secondary school textbooks. Instead, the dominant approach is algebraic, dissociated from the measurement of objects: the square root appears with a strong algebraic character, as an algebraic operator and through some aspects of algorithm for calculations (reinforced by the “ $\sqrt{ }$ ” key in calculators). In high school, the set of real numbers appears to be introduced almost as a "big bag” (p. 59), based on the initial perception of "number", independent of their arithmetic nature; the real line is also introduced. Both for secondary and for high school, Bronner states that a great number of exercises are based on the algebra of radicals, and on the formal rules for calculations and for transforming different writings. It is also rare, in secondary school, to see the name "irrational number" associated to square roots, these numbers being labelled mostly in high school. He uses the term institutional didactic void to refer to the lack of an explicit negotiation, both in curricula and in textbooks, for the extension from decimals or rationals to real numbers. In order to reduce this institutional didactic void, Bronner identifies two main strategies in high school textbooks: 1) to emphasise the rules for the calculation with different types of numbers (being these rules sometimes those used to define a field), but without any indication of the set of reference for these calculations, or the nature of the numbers implied; 2) to present the different types of numbers, the different sets, and the notations for each set. The presentation of real 
numbers, which began with definitions and the presentation of different sets, continues with the object real line. This mathematical knowledge to be taught (Barbé, Bosch, Espinoza and Gascón 2005) plays an important role in teachers' practices, being one of the elements which restrict the choices made by teachers. As such, it is also important to have tools to analyse this knowledge.

\section{Theoretical approach}

Our analysis of how textbooks introduce irrational and real numbers follows an institutional approach, taking into account institutional choices and their repercussions (Chevallard's anthropological theory, 1999), and acknowledging the key role that textbooks play in the institution "secondary mathematics teaching” (SMT), as we view textbooks as being a significant element of the relationship with real and irrational numbers of the SMT institution. Our work coincides with Bronner's (1997) perspective, that teachers are subject to an institution greater than SMT, which consists of the SMT institution and of the practices developed by the textbooks (cf. p. 60). Moreover, we build on his work by considering a greater and more contemporary sample of textbooks.

Chevallard's (1999) anthropological theory attempts to achieve a better understanding of the choices made by an institution when organising the teaching of a topic, and the consequences of these choices on the significance given to the topic taught, as well as on the learning achieved. Chevallard recognises that mathematical objects are not absolute objects, but entities which arise from the practices of given institutions and that, in the end, every human activity consists of completing a certain type of task. These practices may be described in terms of: tasks ( $t$, being $T$ a type of tasks); techniques $(\tau)$ used to complete these tasks; a discourse (technology, $\theta$ ) which both justifies and explains the techniques, allowing to think of or to produce these 
techniques; and a theory which includes the given discourse $(\Theta)$. This framework postulates that every human activity generates an organisation that Chevallard identifies as $[T / \tau / \theta / \Theta]$ and designates as praxeology, or praxeological organisation.

A praxeological analysis characterises the institutional relationship with a given mathematical object within a given institution. In particular, we can identify the practical block (or know-how), which is formed by the first two elements (types of tasks and techniques). However, we can rarely find human practices without a discourse to describe, explain and justify what is done, which leads us to identify the knowledge block (or theoretical block) of mathematical activity (including the technology and the theory), which provides the mathematical discourse necessary to justify and to interpret the practical block. All these elements are fundamental aspects of the anthropological model of mathematical activity which can be used to describe mathematical knowledge. These four basic elements form what is called mathematical praxeological organisations. For instance, for the task identify whether a given number is rational or irrational, different techniques may be used, depending on the way the number is expressed (as an addition of two numbers, as a quotient of integers, as a square root...), which may help to solve the task. These different techniques can be explained according to different technological discourses ("a quotient of integers is always a rational”, "the addition of a rational and an irrational is always an irrational”...), which make sense and are justified by a greater framework of notions, properties, etc.

According to this theory, the teacher, in organising the teaching of a given topic, needs to create a specific mathematical organisation in a particular educational institution. To do so, she or he can refer to curricula documentation, textbooks, assessment tasks, national tests, etc., all of which are considered components of a given mathematical organisation. This is how the educational institution "informs" the teacher 
about what mathematics to teach and how to do so (Barbé et al 2005, p. 240), which in turn shapes the mathematical knowledge to be taught. In order to analyse the mathematical praxeological organisations that the institution SMT privileges to introduce irrational and real numbers through textbooks, we analyse how their introduction is organized. We also focus on the types of tasks that are used most often in the textbooks when introducing these topics, as we seek to determine whether textbooks establish a complete praxeological organisation (which accounts for the quartet $[T / \tau / \theta / \Theta])$, or just a partial organisation focusing on the practical block $[T / \tau]$. We will seek to characterise local mathematical organisations (MO), obtained by the integration of MOs to solve a specific type of problems (punctual mathematical organisations), but sharing the same technological discourse (see Barbé et al 2005, for more details).

\section{Methodology}

\section{Sampling}

For our research, we use empirical data from a selection of textbooks used in Brazilian public schools and approved by the Brazilian Ministry of Education. Our focus in this paper is not to make a portrait of the pedagogical organization of Brazilian textbooks as a specific case. Rather, we use the sample of Brazilian textbooks as an example that will allow us to raise and to discuss some questions which we believe to have general parallels with the teaching of real numbers worldwide, and to assess the usefulness of an anthropological approach in analysing textbooks.

In Brazil, elementary education is organised in three sections: fundamental school I (grades 1 to 5, ages 6 to 10), fundamental school II (grades 6 to 9, ages 11 to 14), and middle school (grades 1 to 3, ages 15 to 17), being the two last sections the 
equivalent of secondary education. Textbooks used in public schools are distributed for free to the students and chosen by the school out of a list of textbooks previously approved by the Ministry of Education, through the National Textbook and the National Middle School Textbook Programs (PNLD and PNLEM, initials in Portuguese). Textbooks must be submitted by authors or editors to PNLD and PNLEM assessments in full sets for each of the elementary education sections: there are 5 books for fundamental school I, 4 books for fundamental school II, and 3 books for middle school. The assessment process for the sets of textbooks is mainly based on referrals by experts.

All the textbooks sets included in our sample had been approved by the PNLD and PNLEM programs of the Ministry of Education in the latest assessment processes: 9 sets for fundamental II (out of 16 approved in the last assessment process, in 2008) and 5 sets for middle school (out of 8 approved in the last assessment process, in 2007), all of them chosen randomly. We decided to restrict ourselves to the textbooks approved by the Ministry for two reasons: 1) these textbooks reach all the public schools in the country, and 2) due to the evaluation process, they have been assessed with didactic, pedagogical, conceptual, and structural criteria. The list of textbooks in our sample is given in the tables 1 and 2, below.

Real numbers are usually introduced during fundamental school II, grade 8 (age 13) and used until the end of middle school. Therefore, we analysed the books corresponding to grades 8 and 9 for each title in the Fundamental School II sample; and the full sets for each title in the Middle School sample. 


\begin{tabular}{lll}
\hline Code & Set Title & Authors / Year of Publication \\
\hline F1 & Novo Praticando Matemática & Andrini, Á. \& Zampirolo, M. (2002) \\
\hline F2 & Matemática Hoje é Feita Assim & Bigode, A. (2006) \\
\hline F3 & Tudo é Matemática & Dante, L. (2005) \\
\hline F4 & Matemática para Todos & Imenes, L. \& Lellis, M. (2002) \\
\hline F5 & Matemática e Realidade & Machado, A., Iezzi, G. \& Dolce, O. (2005) \\
\hline F6 & Matemática - Idéias e Desafios & Mori, I. \& Onaga, D. (2006) \\
\hline F7 & Ideias \& Relações & Siedel, C., Peracchi, E. \& Estephan, V. (2005) \\
\hline F8 & Matemática & Souza, M \& Spinelli, W. (2002) \\
\hline F9 & Projeto Araribá - Matemática & (2006) \\
\hline
\end{tabular}

Table 1. Sample - Fundamental School II textbooks sets

\begin{tabular}{lll}
\hline Code & Set Title & Authors / Year of Publication \\
\hline M1 & Matemática Completa & Bonjorno, J., Giovanni, J. \& Júnior, J. (2005) \\
\hline M2 & Matemática & Dante, L. (2005) \\
\hline M3 & Matemática Aula por Aula & Filho, B. \& Silva, C. (2003) \\
\hline M4 & Matemática & Paiva, M. (2004) \\
\hline M5 & Matemática Ensino Médio & Smole, K., Kiykawa, R. \& Diniz, M. (2005) \\
\hline
\end{tabular}

Table 2. Sample - Middle School textbooks sets

Despite the fact that every public school in Brazil has a computer lab, as required by central government policies, digital technologies have had little impact on classroom practices and on the design of instructional materials. Consequently, textbooks rarely focus on activities employing digital technologies for the teaching of real numbers. Consequently,, textbooks which are mostly based on traditional penciland-paper exercises play a central role in the classroom approach.

\section{Data analysis}

Data analysis was conducted on two complementary levels: the first level analyses the structure of the theoretical parts of the textbooks, while the second level focuses on the tasks (and the ways to solve them) privileged by these textbooks and attempts to identify the praxeological organisation which is representative of our sample. Our analysis took into account information from all individual textbooks to draw a 
comprehensive picture of the whole sample of textbooks. Then, we cross-examined the results in order to view possible general trends and to draw a portrait of how the SMT institution introduces real numbers through textbooks. We are aware of the fact that deeper analyses can be done, such as characterising in detail the MO in a given textbook or analysing the use of real numbers in other sections of the textbooks. Other works analysing textbooks following an anthropological approach (e.g. Barbé et al 2005, Kouidri 2009, Xhonneux \& Henry 2011) usually analyse smaller samples, which allows for deeper analyses. However, given the size of our sample, we focused our primary analyses on achieving a global portrait of the introduction of real numbers and restricted ourselves to the chapter dedicated to these numbers, generalising in some way Bronner's work (1997). Deeper analyses of larger organisations, characterising MOs as in Barbé et al (2005) will be the source of future papers.

\section{Level 1: Theory (definitions, examples, and properties)}

On this first level, we studied how irrational and real numbers are introduced. For this purpose, definitions, examples and properties were analysed as a whole, paying particular attention to the articulation and the coherence of their organisation.

\section{Level 2: Task mapping}

At this level, we identified the main tasks proposed by the textbooks. For each task, we identified the techniques proposed to solve it, as well as the technologies used to explain these techniques. We paid special attention to whether this technology was implicit or explicit in the chapter concerning real numbers. Thus, we aimed to identify the praxeological organization which is predominant in our sample of textbooks. Due to space limitations, we will only give examples of some tasks and their analysis. The 
main tasks we identified are the following:

- Classifying a given number as rational or irrational $\left(T_{C R}\right)$ : students are given examples of real numbers, expressed in different forms ${ }^{\mathrm{ii}}$ (such as decimals, fractions, radicals, and other symbolic expressions involving the former) to decide whether they are rational or irrational.

- Determining a fraction equal to a rational number given in decimal writing $\left(T_{F R}\right)$ : finding a fraction equal to a given periodic number by some general procedures.

- Finding a rational or irrational number between two given numbers $\left(T_{B E T}\right)$ : involving arithmetic mean values or adjusting decimal representations.

- Finding a finite decimal approximation for a given irrational number $\left(T_{A P P}\right)$ : consisting of using finite decimal approximations for arithmetic expressions involving irrational numbers, given the finite decimal approximations for these irrational numbers.

- $\quad$ Ordering real numbers $\left(T_{O R D}\right)$ : ordering numbers in fraction or decimal representations.

- Representing numbers in the real line $\left(T_{R L}\right)$ : associating numbers in fraction or decimal representation with points on the real line.

It is also important to mention that tasks exploiting digital technologies on the approach to real numbers are (almost completely) absent from Brazilian textbooks. Even in the tasks of type $T_{A P P}$, no reference to the use of computers or calculators was found.

\section{Data discussion}

\section{Level 1: Theory (definitions, examples, and properties)}

The didactic process of the introduction of real numbers requires a first encounter with 
the MO in question ${ }^{\mathrm{iii}}$. In the case of real numbers, textbooks do not seem to be explicit enough and do not answer to questions such as: What mathematical knowledge is to be taught? Why is it important? Why is it useful? Instead, they seem to privilege the introduction of a set of definitions and properties.

Textbooks generally begin by providing some definitions, without problematising the new content or justifying its need. The definitions given by the textbooks to introduce irrational numbers were classified into two types: "an irrational number is a number which cannot be written in the form of a fraction” $\left(D_{A}\right)$, and "among the numbers written in decimal form, there are numbers with infinite nonperiodic decimals, called irrational numbers” $\left(D_{B}\right)$. In our sample, 5 textbooks (F1, F2, F4, F5, F8) define irrationals using $D_{A}$ and 9 textbooks (F3, F6, F7, F9, M1, M2, M3, M4, M5) using $D_{B}$. In particular, F7 does not clearly state a definition for irrational numbers, but $D_{B}$ is presented through a set of exercises.

Despite the fact that definitions $D_{A}$ and $D_{B}$ are mathematically equivalent, none of the textbooks presents an argument to establish this equivalence. However, in order to solve certain tasks, some textbooks use $D_{A}$ (including some that defined irrationals trough $D_{B}$ ) and all of them use $D_{B}$ (including the ones that defined irrationals through $\left.D_{A}\right)$. For instance, textbook F5, which introduces irrational numbers through $D_{A}$, gives examples claiming that some numbers in decimal representation are irrational, without providing any argument to support such a statement (figure 1). All the textbooks introduce real numbers in the same way, by the following statement: "any rational or irrational number is a real number” $\left(D_{C}\right)$ (figure 2). 


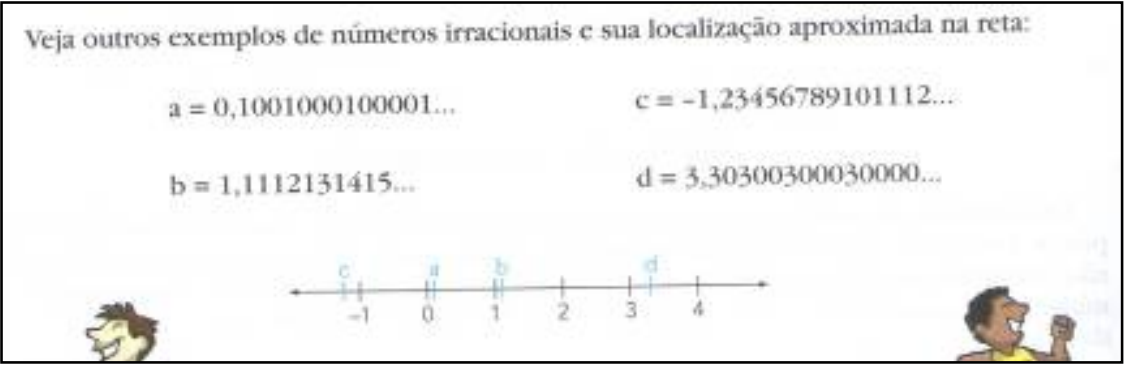

Figure 1. Examples of irrational numbers in textbook F5 (See other examples of irrational numbers and their approximate localization on the line).

\section{Números reais}

Vimos que todos os números naturais e todos os numeros inteiros sao números racionais.

luntando os números racionais e os números irracionais num único conjunto, obtemos o conjunto dos números reais, que é denotado por $R$.

Figure 2. Definition of real number in textbook F1 (We saw that all natural and integer numbers are rational numbers. If we put together rational numbers and irrational numbers in a single set, we obtain the set of real numbers, which is denoted by IR).

This strategy of presenting the different types of number, the different sets, and the notations for each set seems to correspond to the strategies that Bronner (1997) identified to reduce the institutional didactic void. However, we will see that this is done without setting the elements to enrich this first encounter and developing a significant MO. It is important to note that, in order to define irrational numbers, $D_{A}$ and $D_{B}$ presuppose, respectively, the existence of another type of numbers which are not fractions, and which have infinite non-periodic decimal representations. Thus, $D_{A}$ and $D_{B}$ do not establish the existence of a new kind of number. Rather, they label as irrationals a class of numbers within a set which is assumed to be previously existent (and cannot be other than the real numbers). However, in these textbooks, the definition of real number not only comes after the definition of irrationals, but also depends on it, since $D_{C}$ presents a real number as one that is either rational or irrational. Therefore, since these definitions are mutually dependent, from a mathematical point of view, they could not even be considered as proper definitions. Furthermore, from a pedagogical 
standpoint, this analysis suggests serious difficulties associated with the definitions presented in the textbooks, since the object of the definition is assumed to be previously known, without any problematisation for its existence. We see here an example of circular argumentation, which has also been identified by Barbé et al (2005), and which constitutes also in their case "one of the weaknesses of the "mathematical knowledge to be taught”' (p. 262). In particular, $D_{B}$ is based on the assumption that every real number admits a decimal representation. Surprisingly, the acceptance of this property by students appears to be taken for granted, as a transparent rule which does not need justification (Barbé et al 2005, p. 250). Moreover, the textbooks do not seem to take into account the difficulties identified by research (Fischbein et al 1995; Robinet 1986; Soares et al 1999) in defining or recognising an irrational number.

Another problem we find in these definitions is that $D_{A}$ characterizes rationals as "fractions", and irrational as "numbers that cannot be written as fractions". However, the characterisation concerning the nature of both the numerator and the denominator of the fractions as integers is absent. This can later produce some confusion between fractions of whole numbers, and the more general notion of ratio ${ }^{i v}$.

Among the 14 textbooks of our sample, eight (F2, F4, F5, F6, F9, M1, M3, M5) introduce irrational numbers through examples of numbers which are not rational, which are presented before the definition, (allegedly) pointing out to the existence of a "new" type of numbers. Six out of these eight textbooks use $\sqrt{2}$ as the introductory example, four of which through the measurement of the diagonal of a square and directly using the definitions $D_{A}$ or $D_{B}$, and other two through the decimal representation. The other two textbooks use examples of numbers with infinite nonperiodic decimal expansions. We can see that the use of decimal expansions is privileged as ostensive, without any argumentation that infinite non-periodic decimal 
expansions cannot be the result of a division of integers (again, as if this fact were transparent).

In all the textbooks, the examples concerning irrational numbers are mainly used to illustrate definitions and properties. That is, the statement of a definition or a property is accompanied by some examples verifying it (figure 3). The numbers $\sqrt{2}, \sqrt{3}$, and $\pi$ are among the examples commonly used in the textbooks. The decimal representations of these numbers are assumed to be known (even in the textbooks which only state $D_{A}$ ), but no justification at all for that is provided by any of the books.

\section{$\sqrt{2}$ é um número irracional.}

Os matemáticos mostraram também que existem infinitos números irracionais.

Por exemplo, as raizes quadradas dos números primos:

$\sqrt{3}, \sqrt{5}, \sqrt{11}, \sqrt{13}$... são números irracionais, bem como seus opostos $-\sqrt{3},-\sqrt{5},-\sqrt{11},-\sqrt{13}$.

Figure 3. Statement of properties with no argumentation, from textbook F1 ( $\sqrt{2}$ is an irrational number. Mathematicians also showed that there are infinite irrational numbers. For instance, the square roots of prime numbers: $\sqrt{3}, \sqrt{5}, \sqrt{11}, \sqrt{13} \ldots$ are irrational numbers, as well as their opposites $-\sqrt{3},-\sqrt{5},-\sqrt{11},-\sqrt{13} \ldots)$.

The properties found in the textbooks concern mainly the operations (algebraic closedness for rationals and operations between rationals and irrationals), and the localisation of points on a line. As we mentioned previously, examples are mainly used to illustrate properties. As none of the properties is justified or argued by any other means but the examples (figure 3) (and students are not even informed that corresponding proofs are to be done later on at a higher grade level), this could lead the students to develop an inductive mathematical reasoning, by forming the incorrect idea that a property can be proved through the verification of some examples, developing an approach to proof close to the "naïve empiricism” identified by Balacheff (1987). We can see here yet again that the raison d'être of this set of properties is absent, and serves 
only to solve some tasks which are given to practise them (as we will show later); the choice is to institutionalise them as transparent rules. We can also see here elements of what Bronner (1997) identified as the second strategy to reduce the institutional didactic void: to emphasise the rules for the calculation with these numbers. Seven of the textbooks explicitly state the density ${ }^{\mathrm{v}}$ property of rational numbers as "between any two rational numbers there is always another rational number”, and illustrate it through the arithmetic mean of two given fractions. Three out of these 7 textbooks also use the arithmetic mean to illustrate the more general statement: "between two real numbers there is always another real number”. However the term “density” applied for real numbers is not explicitly mentioned in any of textbooks. Research results concerning difficulties with cardinality and topological properties (as we showed in section 3) seem to be also ignored by the textbooks we analysed.

\section{Level 2: Tasks}

In total, if we consider the types of tasks previously identified, 184 tasks where analysed, including 156 from the textbooks for fundamental school (F, with an average of 17.33 tasks per book) and 28 from the textbooks for middle school (M, with an average of 5.6 tasks per book). These tasks appear in sections with the names: "solved exercises”, “proposed exercises”, “complementary exercises”, and “tests”. Table 3 shows the full distribution of the identified tasks in the textbooks of our sample. Note that there are fewer tasks related to the introduction of textbooks for middle school. This is due to the fact that, in the Brazilian syllabus, real numbers are supposed to be introduced in the last years of fundamental school. 


\begin{tabular}{|c|l|l|l|l|l|l|l|}
\hline \multirow{2}{*}{ Textbooks } & \multicolumn{7}{|c|}{ Types of Tasks } \\
\cline { 2 - 8 } & $T_{C R}$ & $T_{F R}$ & $T_{B E T}$ & $T_{A P P}$ & $T_{\text {ORD }}$ & $T_{R L}$ & Total \\
\hline F1 & 13 & 0 & 5 & 14 & 1 & 3 & 36 \\
\hline F2 & 0 & 0 & 1 & 3 & 0 & 3 & 7 \\
\hline F3 & 5 & 0 & 2 & 8 & 0 & 1 & 16 \\
\hline F4 & 6 & 2 & 0 & 0 & 0 & 0 & 8 \\
\hline F5 & 5 & 2 & 1 & 7 & 8 & 3 & 26 \\
\hline F6 & 5 & 0 & 0 & 12 & 1 & 3 & 21 \\
\hline F7 & 3 & 0 & 3 & 2 & 0 & 1 & 9 \\
\hline F8 & 5 & 2 & 1 & 6 & 1 & 1 & 16 \\
\hline F9 & 3 & 1 & 1 & 8 & 1 & 3 & 17 \\
\hline M1 & 1 & 0 & 0 & 0 & 0 & 0 & 1 \\
\hline M2 & 1 & 1 & 0 & 0 & 1 & 1 & 4 \\
\hline M3 & 2 & 0 & 0 & 0 & 0 & 0 & 2 \\
\hline M4 & 2 & 1 & 3 & 0 & 0 & 2 & 8 \\
\hline M5 & 1 & 2 & 3 & 3 & 1 & 3 & 13 \\
\hline Average F & 5.00 & 0.78 & 1.56 & 6.67 & 1.33 & 2.00 & 17.33 \\
\hline Avarage M & 1.40 & 0.80 & 1.20 & 0.60 & 0.40 & 1.20 & 5.6 \\
\hline
\end{tabular}

Table 3. Distribution of the different tasks in the textbooks of our sample.

The reference mathematical organisation can be structured around three local mathematical organisations (MO) (figure 4). Firstly, the tasks of types $T_{A P P}, T_{B E T}, T_{O R D}$, and $T_{R L}$ are supported by similar technological-theoretical discourses, generating a MO, which we refer to as $\mathrm{MO}_{1}$ - topology of IR. However this discourse, and in which sense it supports the techniques used to solve these tasks is not explicit in the textbooks. We characterise this as being an incomplete organization, with the focus placed on the practical block. Secondly, the tasks of type $T_{C R}$ create a $\mathrm{MO}$, which we will name $\mathrm{MO}_{2}$ - classification. This MO focuses on the problem of defining real and irrational numbers, and on identifying given numbers as belonging to these categories or not. The mathematical discourse is not accompanied by any mathematical practice within the students' experience, and the few technological elements presented (the definitions and the supposedly meaningful properties) seem to be limited to a normative function. Finally, the tasks of type $T_{F R}$, on the contrary, lead to $\mathrm{MO}_{3}$-determining fractions, whose only purpose seems to be to find a fraction equivalent to a given decimal writing, developing no raison d'être or purpose for this type of task, and developing no 
technological discourse to justify the set of rules given to accomplish the tasks. This is quite unfortunate, since this type of tasks could help in the argumentation of some of the theoretical elements of $\mathrm{MO}_{2}$ (generated around $T_{C R}$ ) and could be helpful to start a discussion about the equivalence of the definitions $D_{A}$ and $D_{B}$. Moreover, these three MOs seem to be disconnected, and the common elements which would allow to link them are absent from the textbooks. The consequences of learning this content in such a disconnected way could have an impact on the learning of other topics, as it is the case with limits of functions, which could be organised with MOs around the theory of real numbers (see Barbé et al 2005, p. 243).

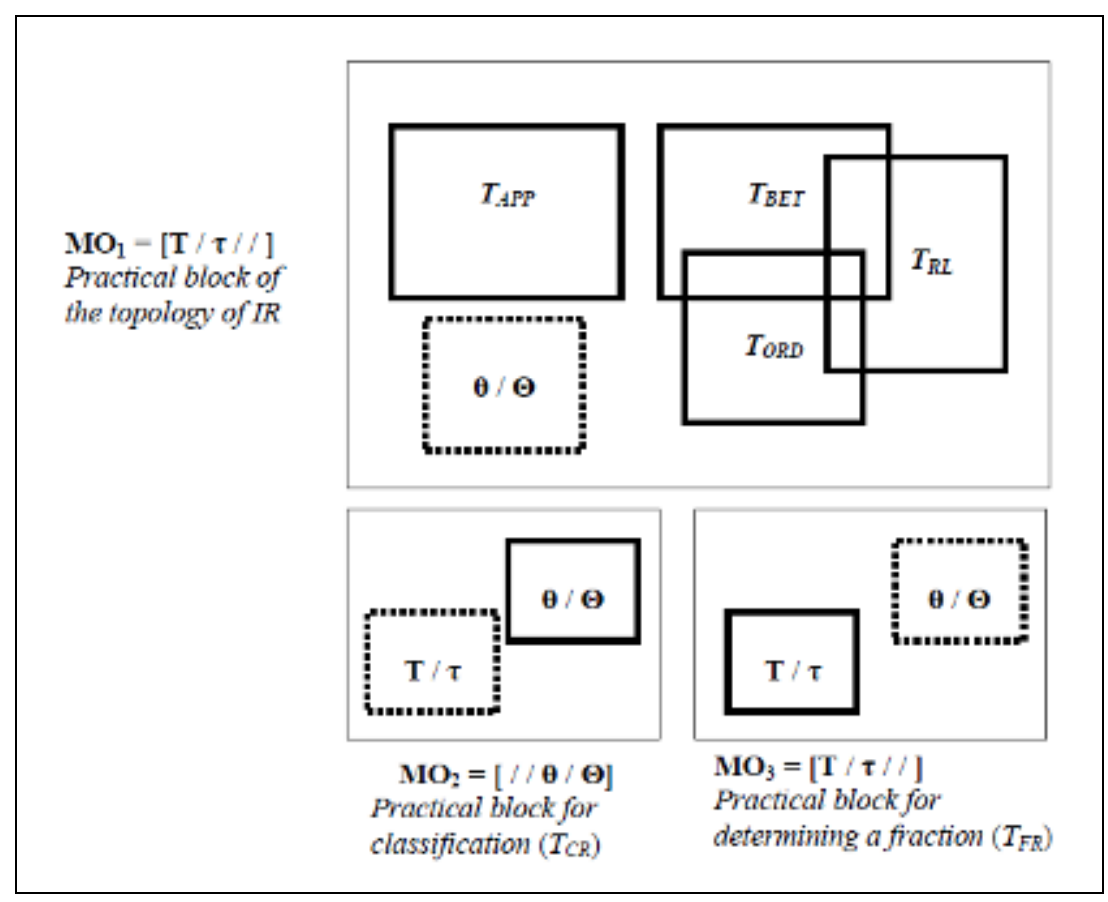

Figure 4. Map of the knowledge to be taught concerning real numbers. The dotted squares refer to the elements which are more implicit, or absent, in the MOs.

To better illustrate the analyses we performed that led us to identify the three MOs described above, we will provide details for two examples of tasks from the categories $T_{C R}$ and $T_{A P P}$. We chose examples from these categories because: 1 ) they belong to the most remarkably frequent types of tasks (table 3); 2) we believe they 
clearly illustrate our argument that the MOs present in the textbooks are not complete. An exhaustive analysis of all the types of tasks can be found in Souto (2010).

Identifying a given number as an irrational (task from the category $T_{C R}$ )

For instance, the specific task $t_{C R-1}$ : “decide whether $5+\sqrt{3}$ is rational or irrational” implies the technique $\tau_{C R-1}$ : "if the number is given by an addition, identify whether both terms are rational or not”. The students are guided to see that as $\sqrt{3}$ is irrational and 5 is rational, the number will be irrational. However, this fact is supported by two facts $\left(\theta_{1}\right.$ and $\left.\theta_{2}\right)$ : "the addition of a rational and an irrational is irrational” and " $\sqrt{3}$ is irrational”, which are not justified (and sometimes not even stated) in any way in the textbooks which propose this specific task. In general, the local MO of these types of tasks uses the following properties:

- Use of the definition of irrational $\left(D_{A}\right.$ or $\left.D_{B}\right)$.

- Use of generic examples: $\sqrt{2}, \sqrt{3}, \pi$.

- Recognising some properties related to the closedness of operations: the sum/difference/product/quotient (with the divisor different from zero) of any two rational numbers is a rational number; the sum/difference/product/quotient of a rational and an irrational is an irrational number.

As we said before, this $\mathrm{MO}_{2}$ uses a standard mathematical discourse which is not accompanied by any mathematical practice within the students' experience, and the tasks seem to lead the students' to simply memorise the technological discourse, which is introduced as transparent rules. Furthermore, the definitions provided assume the existence of irrationals or the irrationality of the generic examples (level 1). All the 
textbooks in the sample use the properties above as a discourse (technology) to justify the immediate techniques of recognition to solve this type of task. However, 12 of them use these properties tacitly, without any clear statement. The two remaining textbooks (F2, M4) present statements for the properties, but do not provide any kind of argument for their validity.

Consequently, the learner might be able to classify some numbers as irrationals, without knowing, however, what it means to be irrational (besides "not being rational”), or being able to explain why these numbers are irrational (besides "because I applied this rule”). Thus, most of the tasks of this MO appear for technological reasons, but this technological discourse is not justified in any way.

Evaluating a symbolic expression by approximation (task from the category $\left.T_{A P P}\right)$

Let's consider the task given by Figure 5:

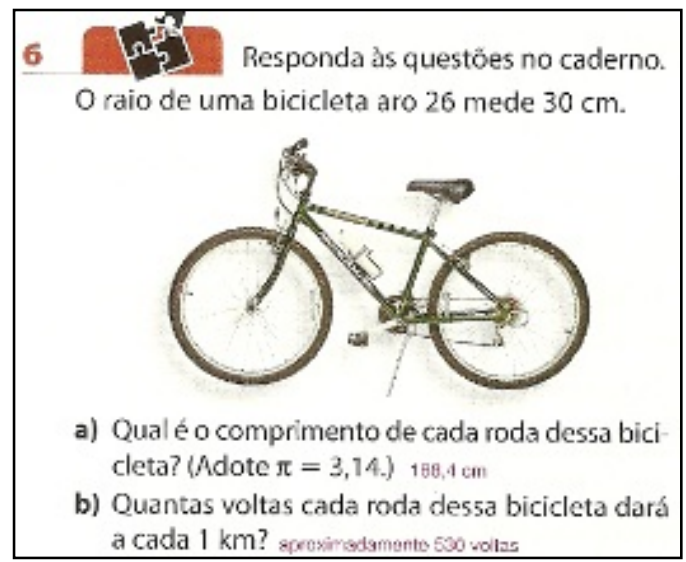

Figure 5. Task asking to approximate the length of a wheel, from textbook F2 (The radius of a bike measures $30 \mathrm{~cm}$. a) What is the measure of each wheel of this bike? (take $\pi=3.14$ ) b) How many turns will each wheel give every $1 \mathrm{~km}$ ?).

The technique to solve the first part of this task, requires knowledge of the formula to calculate the length of a circumference $(2 \times \pi \times r)$, and to substitute $r$ by $30 \mathrm{~cm}$ and $\pi$ by 3.14. This technique is supported by the fact that the length of a circumference 
is given by the expression $2 \times \pi \times r$ (which is not justified, or reasoned, in the textbooks). Note that students are asked to use $\pi$ as 3.14 , and nowhere in the textbook is there any mention of the fact that the student is working with approximations, and not with the irrational numbers themselves.

This type of task often involves evaluating elements of a circumference: radius, given the length or the area; length or area, given the radius... The techniques involved are reduced to simply evaluating by substitution, and the associated explicit technologies are the usual rules for manipulating numeric and symbolic expressions (implicitly, there is the assumption that the student has prior knowledge of decimal developments, and the theories of approximation). Such tasks generally include instructions such as "consider $\pi=3.14$ " and an answer is given, without any kind of warning that the task will only lead to an approximation of the actual answer, since different approximations of $\pi$ would lead to different values for the answer. The textbooks in the sample also use a range of other examples, such as $8+\sqrt{2}, \pi+\sqrt{2}$, $3 \pi$, in which fixed approximations for the numbers involved are given, and an approximation for an expression is asked.

The solution provided for these tasks which represent irrational numbers as finite decimals (without any clear alert that these are approximations) can conflict with the notion (introduced mainly through $D_{B}$ ) of an irrational as a number with infinite non periodic decimal representation, a notion fostered by the very same textbooks. These aspects could be related to some of the phenomena described by Bronner (1997), such as the difficulty of shifting from numbers with finite decimals to numbers with infinite decimals, or the view of irrationals as numbers "which are not exact” (p. 69). 
In this type of task, the praxis block $[T / \tau]$ is constituted by the usual processes of evaluation and calculation; however, once again, the logo block $[\theta / \Theta]$ includes some elements which are not explicit. This situation seems to mirror the findings of Bronner (1997), and could be one of the strategies used to reduce the institutional didactic void.

Because of space limitations, we will only develop these two examples, with some indications of the whole type of task that they represent. More detailed analyses can be found in Souto (2010).Our analyses show that the dominant approach is algebraic, dissociated from the measurement of objects, as Bronner (1997) also identified in his work. Our results seem to coincide with those of Lithner (2004), who stated that tasks for which students need merely to reproduce exemplified techniques are predominant in the textbooks he analysed.

\section{Concluding remarks}

The main contributions of our work are: 1) the use of an institutional approach to analyse the introduction of irrational and real numbers in textbooks and the possible consequences of these institutional choices; 2) the results of our analyses concerning the dominant organisation of the content developed in the textbooks in our sample.

Concerning our first contribution, we consider that the use of Chevallard's approach (1999) has proven to be useful and productive in analysing textbook content and organisation, and that this approach offers specific tools to analyse practices; we plan to deepen these analyses in the future with a smaller sample, making connections with teaching practices, to analyse the mathematical knowledge actually taught (e.g. Barbé et al 2005). Most of the existing research concerning the learning of real numbers uses a cognitive approach, however we found that to analyse how the teaching of real numbers takes place, a purely cognitive approach was insufficient. The tools of the 
institutional approach have allowed us to distinguish, in this preliminary analysis of a large sample (which is rarely found in the literature), some regularities in the way in which textbooks seem to organise the contents and to characterise a dominant praxeological organisation for the teaching of real numbers. Our results, which appear to coincide with those of Bronner (1997), indicate that definitions, properties and examples are articulated, mostly as lists of things to know (or memorise), without fostering the development of technologies to justify the techniques used to solve the proposed tasks, and without making connections between the three main local MOs proposed. The institution SMT seems to favour organisations which mainly focus the practical block through the textbooks, which goes in the same direction than the findings of Barbé et al (2005) about the teaching of limits. This could have important consequences for teaching, as Barbé et al (2005) have postulated: "if the knowledge to be taught is made of a collection of punctual mathematical organisations that are not linked to each other through an operative technological-theoretical discourse, then the possible corresponding spontaneous didactic organisations that the teacher can use will not be able to really integrate the six different moments of the didactic process.” (p. 261).

With regard to our second contribution, considering that the textbooks of our sample are representative of school textbooks used in many countries, the institutional approach has also allowed us to see that the difficulties identified by previous research are not, at least explicitly, taken into account by the textbooks. Our analyses reveal that the praxeologies likely to be generated by the textbooks are quite distant, both at the technical and theoretical level, from academic mathematics. In particular, the textbooks lack coherent and operational definitions of irrational numbers (even in language compatible with secondary school), there is place for many implicit assumptions, and 
the justification of properties is based exclusively on examples. Furthermore, the necessity of introducing these "new" numbers is not problematised, and they are not presented within a significant context or with regards to their utility as a mathematical tool. In general, he tasks these numbers are reduced to perform do not favour the development of a coherent discourse or a mathematically sound theory. The properties of the operations are highlighted with detriment to aspects regarding the structure of the real line and with a general disregard to the research results concerning difficulties in learning real and irrational numbers and some of their arithmetic and topological properties, echoing Bronner’s (1997) results which identified an over-emphasis on the application of rules, but the absence of the problem of measurement. To sum up, the mere presentation of a set of unjustified rules and procedures is unlikely to contribute to students' learning of real numbers. However, this seems to be the choice made by the authors of the textbooks in order to avoid mathematical formalism, or to reduce the institutional didactic void identified by Bronner (1997). We have characterised the praxeologies in our sample as incomplete, mainly focusing on the practical block, which resembles the findins of other works (e.g. Winslow, 2006). In this sense, it would be difficult to expect the students to successfully accomplish a first type of transition (see Winslow, 2006, p. 3), without developing explanations for certain techniques; the second type of transition, more characteristic of the university level, would also be affected.

An analysis through the lens of the anthropological theory of didactics indicates that the existing organization for introducing real numbers will not make a significant contribution to the mathematical culture and skills desirable for students to develop at the end of secondary school, nor will it prepare them for their undergraduate studies, particularly in the case of students who intend to pursue scientific careers. These 
implications are particularly salient as we know that textbooks represent a fundamental resource for teachers and play a central role in their pedagogical choices (Howson 1995; Reys and Reys 2007; Sträßer 2009). The study of teaching practices and how these practices are related to the presentation of real numbers in the textbooks will be the source of future research, which is currently under development by the authors.

${ }^{\mathrm{i}}$ Of course, algebraic irrational numbers can be introduced through the solution to some polynomial equations; however, since they are not transcendental numbers, the need of these algebraic numbers can be seen as a motivation to go further than the rationals, but it is not enough to justify the need of the set of real numbers as a mathematical structure.

${ }^{\text {ii }}$ In this sense, the anthropological theory recognises the importance of ostensives (e.g. Bosch and Chevallard 1999), which allow the manipulation of mathematical objects.

iii These different moments of the didactic process are explained in Chevallard (1999). For a summarized version, see Barbé et al (2005).

${ }^{\text {iv }}$ For instance, $\pi$ is defined as the ratio between the length and the diameter of a circle, but it is not a fraction, since it cannot be expressed as a division of whole numbers.

"In this paper, we use the term "density property" in the following sense: a metric space $(E, d)$ is said to be dense if for every element $x \in E$, and for every neighborhood $U$ of $x$, there is point $y \in U, y \neq x$. Our choice for using this terminology (which is not necessarily standard in mathematical literature) is due to the fact that it is broadly used, with this sense, in Brazilian mathematics textbooks.

\section{References}

Balacheff, N. 1987. Processus de preuve et situations de validation. Educational Studies in Mathematics 18: 147-176.

Barbé, J., M. Bosch, L. Espinoza and J. Gascón. 2005. Didactic restrictions on the teacher's practice: the case of limits of functions in Spanish high schools. Educational Studies in Mathematics 59: 235-268.

Bergé, A. 2008. Students’ perception of the completeness property of the set of real numbers. Presented at the $11^{\text {th }}$ International Conference on Mathematics Education (ICME11), Monterrey (Mexico). Available at http://tsg.icme11.org/tsg/show/18

Bosch, M. and Y. Chevallard. 1999. La sensibilité de l'activité mathématique aux ostensifs. Recherches en Didactique des Mathématiques 19, nº 1 : 77-124. 
Bronner, A. 1997. Les rapports d'enseignants de troisième et de seconde aux objets « nombre réel » et « racine carrée ». Recherches en Didactique des Mathématiques 17, $n^{\circ} .3: 55-80$.

Chevallard, Y. 1999. L’analyse des pratiques enseignantes en théorie anthropologique du didactique. Recherches en Didactique des Mathématiques 19, nº 2 : 221-266.

Fischbein, E., R. Jehiam, and D. Cohen. 1995. The concept of irrational number in highschool students and prospective teachers. Educational Studies in Mathematics 29, n'. 1: 29-44.

Giraldo, V., A.S. González-Martín, and F.L. Santos. 2009. An analysis of the introduction of the notion of continuity in undergraduate textbooks in Brazil. In Proceedings of the $33^{\text {rd }}$ Conference of the International Group for the Psychology of Mathematics Education, ed. M. Tzekaki, M. Kaldrimidou and H. Sakonidis, Vol. 3, 81-88. Thessaloniki, Greece: Aristotle University of Thessaloniki.

González-Martín, A.S., E. Nardi, and I. Biza. 2011. Conceptually-driven and visuallyrich tasks in texts and teaching practice: the case of infinite series. International Journal of Mathematical Education in Science and Technology 42, $\mathrm{n}^{\circ} .5$ : 565589.

Howson, G. 1995. Mathematics textbooks: A comparative study of grade 8 texts (Vol. 3). Vancouver: Pacific Educational.

Katz, V.J. 1992. A History of Mathematics: An Introduction. New York: Harper Collins. Kouidri, K. 2009. Problèmes de l'enseignement de l'intégration au début de l'université en Algérie. Annales de Didactique et des Sciences Cognitives 14: 123-152

Lithner, J. 2004. Mathematical reasoning in calculus textbook exercises. Journal of Mathematical Behavior 23: 405-427.

Raman, M. 2004. Epistemological messages conveyed by three high-school and college mathematics textbooks. Journal of Mathematical Behavior 24, $\mathrm{n}^{\circ}$. 4: 389-404.

Reys, B.J., and R.E. Reys. 2007. An agent of change: NSF sponsored mathematics curriculum development. NCSM Journal of Mathematics Education Leadership $10, n^{\circ} .1: 58-64$.

Robinet, J. 1986. Les réels: quels modèles en ont les élèves? Educational Studies in Mathematics 17: 359-386. 
Sirotic, N., and R. Zazkis. 2007. Irrational numbers: the gap between formal and intuitive knowledge. Educational Studies in Mathematics 65, $n^{\circ} .1$ : 49-76.

Soares, E.F.E., M.C.C. Ferreira, and P.C. Moreira. 1999. Números reais: concepções dos licenciandos e formação Matemática na licenciatura. Zetetiké 7, nº 12: 95117.

Souto. A. M. 2010. Análise dos Conceitos de Número Irracional e Número Real em Livros Didáticos da Educação Básica. Master Thesis, Rio de Janeiro: Universidade Federal do Rio de Janeiro.

Sträßer, R. 2009. Instruments for learning and teaching mathematics. An attempt to theorise about the role of textbooks, computers and other artefacts to teach and learn mathematics. In Proceedings of the $33^{\text {rd }}$ Conference of the International Group for the Psychology of Mathematics Education, ed. M. Tzekaki, M. Kaldrimidou and H. Sakonidis, Vol. 1, 67-81. Thessaloniki, Greece: Aristotle University of Thessaloniki.

Stylianides, G.J. 2009. Reasoning-and-proving in school mathematics textbooks. Mathematical Thinking and Learning 11, $\mathrm{n}^{\circ} .4$ : 258-288.

Wagner, D. 2012. Opening mathematics texts: Resisting the seduction. Educational Studies in Mathematics 80, $\mathrm{n}^{\mathrm{0}}$ 1-2: 153-169.

Winslow, C. 2006. Transformer la théorie en tâches : la transition du concret à l'abstrait en analyse réelle. In Actes de la XIIIème École d'Été de Didactique des Mathématiques, ed. R. Rouchier and I. Bloch, 1-12. Grenoble: La Pensée Sauvage Éditions.

Xhonneux, H. and V. Henry, V. 2011. A didactic survey of the main characteristics of Lagrange's theorem in mathematics and in economics. In Proceedings of the $7^{\text {th }}$ Congress of the European Society for Research in Mathematics Education (CERME7), ed. M. Pytlak and E. Swoboda, 2123-2133. Rzeszów, Poland: University of Rzeszów.

Zazkis, R., and N. Sirotic. 2004. Making sense of irrational numbers: focusing on representation. In Proceedings of the $28^{\text {th }}$ Conference of the International Group for the Psychology of Mathematics Education, ed. M. Høines and A.B. Fugelstad, Vol. 4, 497-504. Bergen, Norway: PME. 